\title{
RANCANG BANGUN ALAT PENGERING DENGAN SISTEM PENGERINGAN GABUNGAN PERPINDAHAN PANAS TIDAK LANGSUNG DAN VAKUM
}

\author{
Jaka Rukmana ${ }^{1}$ \\ Yazid Bindar $^{2}$ \\ ${ }^{1}$ Program Studi Teknologi Pangan, Fakultas Teknik, Universitas Pasundan, Jl. Dr.Setiabudi No 93, Bandung, \\ 40153, Indonesia \\ ${ }^{2}$ Program Studi Teknik Kimia, Fakultas Teknologi Industri, Institut Teknologi Bandung Jalan Ganesha 10 \\ Bandung 40132
}

Email: jakarukmana@unpas.ac.id

\begin{abstract}
Abtrak
Tujuan umum dari penelitian ini adalah untuk pencapaian ketahanan pangan Indonesia melalui pembangunan industri hilir berbahan baku tepung nangka. Tujuan khususnya adalah untuk melakukan kajian mengenai produksi tepung nangka menggunakan alat pengering dengan sistem pengering gabungan antara perpindahan panas tidak langsung dan kondisi vakum. Penelitian ini terbagi kedalam 3 tahap. Tahap pertama adalah merancang alat pengering, uji performa alat pengering, dan penentuan kondisi optimum untuk produksi tepung nangka. Tahap kedua adalah pengujian umur simpan tepung nangka. Tahap ketiga adalah uji kegunaan tepung nangka yang dihasilkan. Hasil penelitian tahap pertama menunjukan bahwa alat pengering hasil perancangan memiliki performa yang baik. Hal ini ditunjukan dengan nilai humiditi dari ruang pengering sebesar $0,0186 \mathrm{~kg}$ $\mathrm{H}_{2} \mathrm{O} / \mathrm{kg}$ udara kering dan tekanan yang stabil selama proses pengeringan yaitu sebesar $-61,5 \mathrm{cmHg}$.

Kata kunci: pengeringan, pindah panas tidak langsung dan vakum, produksi tepung nangka
\end{abstract}

Abstract
The general objective of the study of "Production of Jackfruit Flour By Applying Combined Vacuum And Indirect Heat Transfer Method of Drying" is to improve Indonesian food security through the development of downstream industries with raw material of jackfruit flour. The specific objective of this research is to study the jackfruit flour production using a dryer with a drying system combined with indirect heat transfer and vacuum conditions. This study is divided into three phases. The first phase is the dryer's design, test tool of no-load dryer's performance, and the determination of the optimum conditions for producing the jackfruit flour. The second phase is to test the shelf life of the jackfruit flour. The third phase of this research is to test the usefulness of jackfruit flour.The research results of the first phase showed that the designed dryer has a good performance. This is evidenced by the humidity value and stable pressure during the drying process. The humidity value is $0,0186 \mathrm{~kg} \mathrm{H}_{2} \mathrm{O} / \mathrm{kg}$ dry air and the pressure is stable of $-61,5 \mathrm{cmHg}$.

Key word: driying, combined vacuum and inderect heating, production of jackfruit flour.

\section{Pendahuluan}

Tanaman nangka (Artocarpus heterophyllus Lamk) adalah jenis tanaman tropis yang banyak tumbuh di Indonesia. Pemanfaatan tanaman nangka masih terbatas sehingga masyarakat hanya mengkonsumsi daging buah segarnya saja. Hampir semua bagian tanaman nangka dapat dimanfaatkan dalam kehidupan manusia. Batang tanaman nangka dapat dimanfaatkan sebagai sumber kayu untuk pembuatan perkakas rumah tangga, bahan bangunan, dan sumber biomassa energi. Akar dan getahnya dapat dimanfaatkan sebagai obat tradisional. Biji nangka dapat diolah menjadi makanan kecil dengan cara direbus. Buah nangka yang masih muda dapat diolah menjadi sayur. Buah nangka yang sudah masak dapat dimakan segar atau dapat diolah menjadi aneka makanan. Kulit buah nangka kering dapat dimanfaatkan sebagai sumber biomassa energi.
Produksi buah nangka mengalami fluktuasi dari tahun 2003 sampai tahun 2013. Produksi buah nangka mencapai 578.327 ton pada tahun 2010 . Produksi buah nangka mengalami peningkatan sebesar $13,2 \%$ pada tahun 2011 menjadi 654.808 ton dan pada tahun 2012 mengalami peningkatan kembali menjadi 663.930 ton. Produksi buah nangka pada tahun 2013 menurun sebesar 11,7\% menjadi 586.366 ton. Ketidakstabilan produksi buah nangka di Indonesia disebabkan belum ada dorongan bagi para petani untuk menjadikan tanaman nangka sebagai tanaman utama di kebun mereka. Nangka hanya dipelihara di pekarangan rumah atau di kebun buah campuran. Tanaman nangka ditanam sebagai tanaman tumpang sari saja karena buahnya mudah sekali busuk dan tidak dapat dilakukan perdagangan ekspor. Prospek pengembangan buah nangka sebenarnya dapat dikatakan cukup cerah tetapi masih jarang 
perkebunan nangka yang dikelola dengan pendekatan agribisnis.

Konsumsi buah nangka sangat terbatas apabila mereka dimakan dalam keadaan segar. Oleh karena itu penanganan pasca panen untuk meningkatkan nilai guna ketika produktivitasnya tinggi sangat diperlukan. Produktivitas tanaman nangka menurut Kementerian Pertanian (2015) adalah sebesar 116,5 ton/pohon (ku/ha). Salah satu upaya untuk meningkatkan nilai guna buah nangka adalah dengan membuat produk setengah jadi. Pengolahan produk setengah jadi merupakan salah satu cara pengawetan hasil panen, terutama untuk komoditas yang memiliki kadar air tinggi, seperti aneka umbi dan buah. Keuntungan lain dari pengolahan produk setengah jadi yaitu sebagai bahan baku yang fleksibel untuk industri pengolahan lanjutan, aman dalam distribusi, serta menghemat ruangan dan biaya penyimpanan. Produksi tepung nangka merupakan alternatif yang diharapkan dapat meminimalkan kerugian akibat tidak terserapnya buah nangka segar di pasar ketika produksi panen berlebih. Produksi tepung nangka akan mendorong munculnya produk-produk yang lebih beragam serta dapat mendorong berkembangnya industri hilir berbahan dasar tepung nangka. Berkembangnya industri hilir berbahan dasar tepung nangka akan mendorong meningkatnya permintaan terhadap produk antara (tepung nangka) sehingga permintaan dan nilai jual komoditas buah nangka akan mengalami peningkatan.

Proses pengeringan adalah salah satu tahapan utama dalam proses pembuatan tepung. Proses pengeringan membutuhkan panas untuk memisahkan cairan dari bahan. Kebutuhan panas biasanya diperoleh dari kondisi pengeringan pada temperatur tinggi, namun beberapa jenis bahan pangan mudah mengalami kerusakan dan penurunan kualitas pada temperatur tinggi. Buah nangka adalah salah satu komoditas yang akan mengalami kerusakan apabila dilakukan pengeringan dengan suhu tinggi. Untuk mengatasi masalah tersebut, maka operasi pengeringan dilakukan pada kondisi temperatur rendah dan tekanan di bawah satu atmosfer. Operasi pengeringan yang mungkin dilakukan pada kondisi temperatur rendah dan tekanan di bawah satu atmosfer adalah pengeringan dengan metode freeze drying dan vacuum drying.

Prinsip dari freeze drying adalah menempatkan bahan pangan dalam kondisi vakum yang tinggi dan mengubah kondisi fisik bahan pangan menjadi es. Selanjutnya terjadi peristiwa sublimasi, yaitu perubahan wujud padat (es) menjadi uap. Oleh karena itu, operasi freeze drying hanya mungkin dilakukan pada kondisi tekanan di bawah triple point dari air yaitu dibawah $0,6 \mathrm{kPa}$. Untuk melakukan metode freeze drying, dibutuhkan peralatan khusus dengan kondisi operasi tekanan yang sangat vakum. Hal ini tentunya membutuhkan biaya yang sangat besar, sehingga operasi pengeringan dilakukan dengan menggunakan alternatif lain. Alternatif lain yang dapat dilakukan adalah pengeringan dengan metode vacuum drying. Prinsip dari vacuum drying adalah menguapkan cairan dari suatu bahan padat. Dengan menggunakan metode ini, sumber panas tidak boleh bersentuhan langsung dengan bahan yang akan dikeringkan atau seringkali disebut dengan indirect-heat drying. Vacuum drying dioperasikan pada kondisi tekanan di bawah satu atmosfer dan diatas triple point dari air.

Beberapa masalah yang seringkali ditemui dalam proses pengeringan diantaranya adalah masalah yang berkaitan dengan mutu hasil pengeringan. Operasi yang dijalankan dalam proses pengeringan adalah operasi yang cukup rumit yang meliputi perpindahan panas dan perpindahan massa. Perubahan fisik dan kimia sering terjadi di dalam proses pengeringan, diantaranya perubahan aroma, warna, tekstur atau sifat padatan lain yang dihasilkan. Masalah selanjutnya adalah yang berkaitan dengan kondisi dan sifat dari bahan yang dikeringkan. Sebagian besar bahan pangan merupakan material yang sensitif terhadap temperatur. Kandungan dalam bahan pangan, seperti karbohidrat, vitamin dan mineral, akan mudah rusak jika dikeringkan pada temperatur tinggi. Oleh karena itu, bahan pangan harus dikeringkan pada temperatur rendah.

\section{Metodologi}

Penelitian dilakukan untuk menghasilkan alat pengering dengan sistem gabungan antara perpindahan panas tidak langsung dan kondisi vakum, mengetahui kondisi operasi optimum pengeringan nangka.

Perpindahan panas dapat didefinisikan sebagai suatu proses berpindahnya suatu energi dari satu daerah ke daerah lain akibat adanya perbedaan temperatur pada daerah tersebut. Ada tiga bentuk mekanisme perpindahan panas yang diketahui, yaitu konduksi, konveksi, dan radiasi. Alat pengering yang dirancang memanfaatkan proses pindah panas secara konveksi dan konduksi.

Perpindahan panas secara konduksi adalah proses perpindahan panas dari daerah yang bertemperatur tinggi ke daerah yang bertemperatur rendah dalam suatu medium (padat, cair atau gas) atau antara medium-medium yang berlainan yang bersinggungan secara langsung sehingga terjadi pertukaran energi dan momentum. Konveksi adalah perpindahan panas karena adanya gerakan atau aliran bagian panas ke bagian yang dingin. Panas yang terjadi di dalam alat pengering merupakan hasil dari proses pemanasan tidak langsung. 


\section{Hasil dan Pembahasan}

Penelitian tahap pertama meliputi perancangan alat pengering dengan sistem gabungan antara perpindahan panas tidak langsung dan kondisi vakum, uji performa alat pengering, dan penentuan kondisi optimum untuk memproduksi tepung nangka.

Tahap perancangan alat pengering dengan sistem gabungan antara perpindahan panas tidak langsung dan kondisi vakum dilakukan mulai dari persiapan, survey lapangan, penentuan dimensi alat yang dirancang, penentuan instrumen, penentuan basic design, detail design, revisi gambar, proses perancangan keseluruhan, dan perakitan alat. Hasil yang diperoleh dari masing-masing kegiatan dapat dilihat pada Tabel 1.

Tabel 1 Jenis dan hasil kegiatan penelitian tahap pertama: perancangan alat pengering

\begin{tabular}{|l|l|}
\hline \multicolumn{1}{|c|}{ Jenis kegiatan penelitian } & \multicolumn{1}{|c|}{ Hasil kegiatan } \\
\hline Persiapan & $\begin{array}{l}\text { Studi literatur dilakukan pada tahap persiapan untuk } \\
\text { mempelajari teori-teori yang berkaitan dengan } \\
\text { perancangan alat. }\end{array}$ \\
\hline Survey lapangan & $\begin{array}{l}\text { Survey lapangan dilakukan untuk mendapatkan data-data } \\
\text { alat maupun sumber tentang mesin pengering yang telah } \\
\text { ada. Data yang dikumpulkan meliputi dimensi, prinsip } \\
\text { kerja, dan sistem mesin pengering yang sudah ada. }\end{array}$ \\
\hline Penentuan dimensi alat yang dirancang & $\begin{array}{l}\text { Dihasilkan dimensi alat yang meliputi dimensi ruang } \\
\text { pengering, dimensi tangki fluida panas, dan dimensi tangki } \\
\text { ejektor. }\end{array}$ \\
\hline Penentuan instrumentasi & $\begin{array}{l}\text { Diperoleh komponen alat yang digunakan dalam } \\
\text { perancangan dan pembuatan alat pengering dengan sistem } \\
\text { gabungan antara perpindahan panas tidak langsung dan } \\
\text { kondisi vakum. }\end{array}$ \\
\hline Pembuatan basic design & $\begin{array}{l}\text { Diperoleh perancangan mesin menggunakan program } \\
\text { autocad. }\end{array}$ \\
\hline Detail design & $\begin{array}{l}\text { Diperoleh perancangan mesin yang lebih lengkap yang } \\
\text { disertai spesifikasi alatnya }\end{array}$ \\
\hline Revisi Gambar & $\begin{array}{l}\text { Diperoleh rancangan mesin yang telah digambar untuk } \\
\text { lebih mempermudah dalam proses perancangan mesin } \\
\text { selanjutnya. }\end{array}$ \\
\hline Proses Perancangan Keseluruhan & $\begin{array}{l}\text { Diperoleh perancangan pada komponen-komponen utama } \\
\text { yang selanjutnya dilakukan proses perancangan mesin } \\
\text { secara keseluruhan dengan merakit komponen-komponen } \\
\text { utama menjadi sebuah mesin. }\end{array}$ \\
\hline Uji Coba Alat & $\begin{array}{l}\text { Dibuat animasi alat pengering menggunakan program } \\
\text { Solid Work }\end{array}$ \\
\hline Animasi & $\begin{array}{l}\text { Diperoleh alat pengering dengan sistem gabungan antara } \\
\text { perpindahan panas tidak langsung dan kondisi vakum yang } \\
\text { direncanakan }\end{array}$ \\
\hline Perakitan Alat & $\begin{array}{l}\text { Diperoleh dan teridentifikasi ketercapaian kondisi tekanan } \\
\text { dan suhu proses. }\end{array}$ \\
\hline
\end{tabular}

Fluida akan memanaskan koil kemudian panas dari koil digunakan untuk memanaskan udara di dalam ruang pengering. Panas yang terbentuk di dalam ruang pengering akan merambat pada bahan secara konduksi. Proses perambatan panas sangat dipengaruhi oleh termal konduktivitas dari bahan. Bahan yang memiliki termal konduktivitas yang rendah akan berdampak pada lambatnya transfer panas pada bahan (Geankoplis, 1993).Fluida pemanas pada alat pengering yang dirancang mengalir melalui sebuah koil berbentuk spiral.
Efektivitas pertukaran energi dapat ditingkatkan dengan cara memilih bahan konstruksi yang memiliki konduktivitas termal yang tinggi. Termal konduktivitas stainless steal cukup tinggi sehingga dipilih sebagai bahan untuk mengkonstruksi koil pemanas. Nilai termal konduktivitas stainless steal sebesar sebesar 45.300 W/m.K (Geankoplis, 1993). 
Pertukaran panas secara tidak langsung terdapat dalam beberapa tipe diantaranya tipe plat, shell and tube, spiral dan lain-lain. Pada pipa spiral terjadi perpindahan panas antara aliran fluida di dalam tube dan di luar tube. Fluida akan memanaskan pipa kemudian panas dari pipa akan memanaskan udara pada ruang pengering. Jenis coil yang berbentuk spiral mempunyai bidang perpindahan panas yang melingkar. Sistem alirannya yang melingkar maka sistem ini dapat melakukan "Self Cleaning" dan mempunyai efisiensi perpindahan panas yang baik, akan tetapi konstruksi seperti ini tidak dapat dioperasikan pada tekanan tinggi.

Fluida yang digunakan untuk memanaskan koil adalah air. Air memiliki termal konduktivitas yang tinggi apabila dibanding cairan lain. Termal konduktivitas air sebesar $0,5690 \mathrm{~W} / \mathrm{m}$.K pada suhu 273K (Geankoplis, 1993). Sistem pengeringan dibuat dalam kondisi vakum sehingga tidak memerlukan panas yang terlalu tinggi. Oleh karena itu dipilih air sebagai fluida pemanas. Pertimbangan lain adalah pertimbangan cost untuk mamanaskan fluida. Semakin tinggi titik didih suatu fluida maka semakin tinggi energi yang diperlukan untuk memanaskan fluida tersebut. Sistem pemanas fluida yang digunakan adalah heater sebesar 1000 Watt.

Ejector merupakan salah satu jenis pompa dinamik yang menggunakan prinsip jet (jet pump) sebagai tenaga penggeraknya. Sistem akan menciptakan ruang bertekanan rendah (vakum). Jet рuтp merupakan pompa sentrifugal biasa yang dipasang alat tambahan berupa jet (ejector), fluida dialirkan melalui nozzle, arus mengecil karena perubahan penampang nozzle, difuser yang membesar secara perlahan ditempatkan didekat mulut nozzle dalam ruang isap, karena kecepatan arus yang meninggalkan mulut nozzle bertambah besar maka tekanan dalam arus akan turun, demikian pula di dalam ruang isap. Pada difuser kecepatan berkurang sehingga tekanan naik kirakira mendekati tekanan atmosfer (apabila fluida dibuang menuju atmosfer). Akibat kejadian tersebut maka tekanan dalam ruang isap juga menurun di bawah tekanan atmosfer, istilahnya terbentuk sedikit vakum yang menyebabkan zat cair dari bejana bawah tersedot naik ke dalam ruang isap dan terjebak oleh arus fluida yang menyemprot dari mulut nozzle. Pertimbangan penggunaan pompa jenis ini karena konstruksi yang sederhana dan juga mudah dalam pengoprasiannya. Selain itu jenis pompa ini tidak memiliki bagian yang bergerak sehingga tidak diperlukan pelumasan, berkurangnya getaran dan dapat didesign dengan berat yang relatif lebih ringan serta kemudahan dalam proses perbaikannya.

\section{Uji Performa Alat Pengering}

Tahap selanjutnya setelah diperoleh alat pengering dengan sistem gabungan antara perpindahan panas tidak langsung dan kondisi vakum maka dilakukan uji performa alat pengering. Tahap pengujian dilakukan untuk mengidentifikasi ketercapaian kondisi proses. Parameter yang diamati meliputi laju pengeringan, suhu, tekanan, $\mathrm{R}_{\mathrm{H}}$ dan humiditi. Pengamatan dilakukan selama 5 jam dengan selang waktu 30 menit setiap pengujian. Hasil pengamatan terhadap $\mathrm{R}_{\mathrm{H}}$ dan humiditi dapat dilihat pada Tabel 2.

Tabel 2 Hasil Pengujian $\mathrm{R}_{\mathrm{H}}$ pada Suhu Pengeringan $50^{\circ} \mathrm{C}$ (Kondisi Atmosferik)

\begin{tabular}{|c|c|c|c|c|}
\hline No. & $\begin{array}{c}\text { Jam } \\
(\text { menit })\end{array}$ & $\begin{array}{c}\mathrm{R}_{\mathrm{H}} \\
(\%)\end{array}$ & $\begin{array}{c}\text { Suhu Bola Basah } \\
\left({ }^{\circ} \mathrm{C}\right)\end{array}$ & $\begin{array}{c}\text { Humiditi } \\
\left(\mathrm{kg} \mathrm{H}_{2} \mathrm{O} / \mathrm{kg} \text { udara kering }\right)\end{array}$ \\
\hline 1 & 30 & 24,8 & 30,0 & 0,018 \\
\hline 2 & 60 & 22,2 & 30,2 & 0,019 \\
\hline 3 & 90 & 21,7 & 30,5 & 0,020 \\
\hline 4 & 120 & 23,3 & 30,0 & 0,018 \\
\hline 5 & 150 & 24,2 & 30,2 & 0,019 \\
\hline 6 & 180 & 22,2 & 30,0 & 0,018 \\
\hline 7 & 210 & 22,5 & 30,5 & 0,018 \\
\hline 8 & 240 & 22,0 & 30,0 & 0,018 \\
\hline 9 & 270 & 22,5 & 30,0 & 0,018 \\
\hline 10 & 300 & 23,8 & 30,0 & $\mathrm{j}$ \\
\hline
\end{tabular}

Tabel 2 memperlihatkan kondisi ruang pengering meliputi RH, suhu bola basah, dan humiditi udara.
Pengujian dilakukan selama 5 jam dengan selang waktu pengecekan 30 menit sekali. 


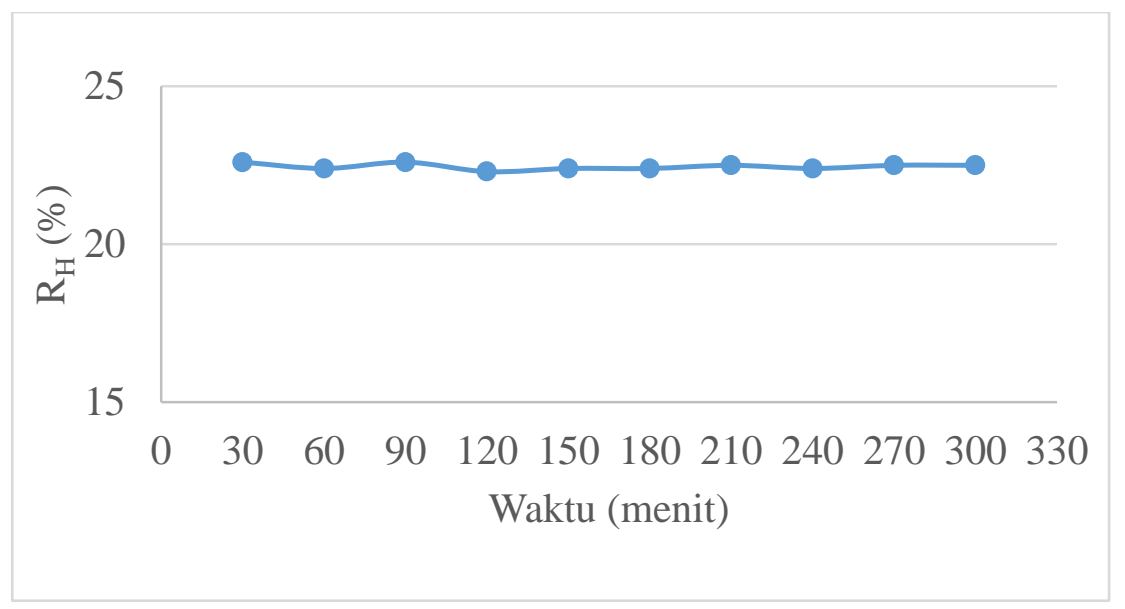

Gambar 5 Grafik pengukuran $\mathrm{R}_{\mathrm{H}}$ di ruang pengering

$\mathrm{R}_{\mathrm{H}}$ adalah jumlah campuran udara dan uap air jenuh yang dinyatakan sebagai persen kelembaban relatif. $R_{H}$ dalam ruang pengering diharapkan sekecil mungkin agar proses pengeringan berjalan lancar. Nilai $R_{H}$ rata-rata selama pengujian adalah sebesar $22,92 \%$. Nilai humiditi pada ruang pengering diperoleh menggunakan humidity chart dengan melihat hubungan anatara suhu bola basah dan suhu bola kering (Geankoplis, 1993). Humiditi adalah banyaknya $(\mathrm{kg})$ uap air yang terkandung di dalam banyaknya (kg) udara kering. Nilai rata-rata humiditi ruang pengering adalah sebesar $0,0186 \mathrm{~kg}$ $\mathrm{H}_{2} 0 / \mathrm{kg}$ udara kering. Nilai humiditi yang dikehendaki adalah sekecil mungkin, karena nilai humiditi menunjukan kandungan uap air di dalam ruang pengering. Semakin kecil kandungan uap air menunjukan bahwa udara di dalam ruang pengering tidak mengandung uap air yang banyak, sehingga diharapkan pengeringan dapat berlansung secepat mungkin.

Tabel 3 Hasil pengujian tekanan pada suhu pengeringan $50^{\circ} \mathrm{C}$ (kondisi vakum)

\begin{tabular}{|c|c|c|}
\hline No & Jam (menit) & Tekanan $(\mathrm{cmHg})$ \\
\hline 1. & 30 & -60 \\
\hline 2. & 60 & -62 \\
\hline 3. & 90 & -62 \\
\hline 4. & 120 & -60 \\
\hline 5. & 150 & -61 \\
\hline 6. & 180 & -62 \\
\hline 7. & 210 & -63 \\
\hline 8. & 240 & -62 \\
\hline 9. & 270 & -61 \\
\hline 10. & 300 & -62 \\
\hline
\end{tabular}

Tabel 3 memperlihatkan kondisi tekanan di ruang pengering. Selama selang waktu pengujian, diperoleh nilai tekanan yang relatif konstan yaitu sebesar $-61,5 \mathrm{cmHg}$.

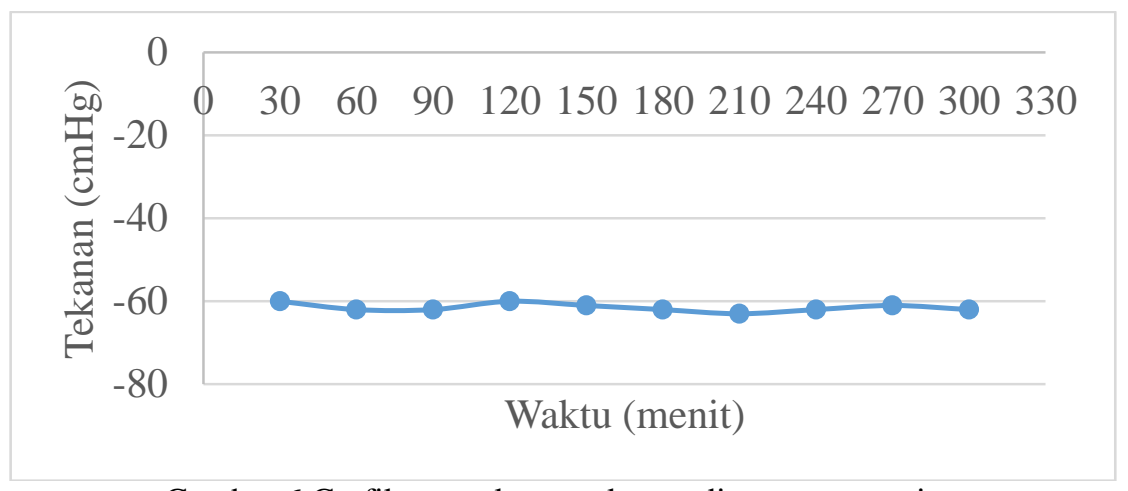

Gambar 6 Grafik pengukuran tekanan di ruang pengering 
Pengujian performa alat pengering menggunakan beban dilakukan dengan membandingkan antara pengeringan udara panas dengan pengeringan gabungan antara udara panas dan vakum. Berdasarkan percobaan yang telah dilakukan, dapat diketahui bahwa semakin lama waktu pengeringan berat sampel akan semakin berkurang. Air yang keluar dari bahan yang dikeringkan akan menjenuhkan udara sehingga kemampuannya untuk menyingkirkan air berkurang.

Pengeringan menggunakan udara panas dihentikan pada saat massa sampel sudah konstan.
Jumlah air yang diuapkan pada sistem pengeringan udara panas mulai konstan pada jam ke-6. Namun pada proses pengeringan gabungan antara udara panas dan vakum sistem dihentikan tidak pada saat massa sampel sudah konstan melainkan dihentikan pada jam ke-6. Hal ini dilakukan untuk melihat sejauh mana perbedaan jumlah air yang diuapkan dan laju pengeringan pada kondisi pengeringan atmosferik dan pengeringan vakum pada waktu pengeringan yang sama.

Gambar 7 menunjukan hubungan antara jumlah air yang diuapkan dengan waktu pengeringan.

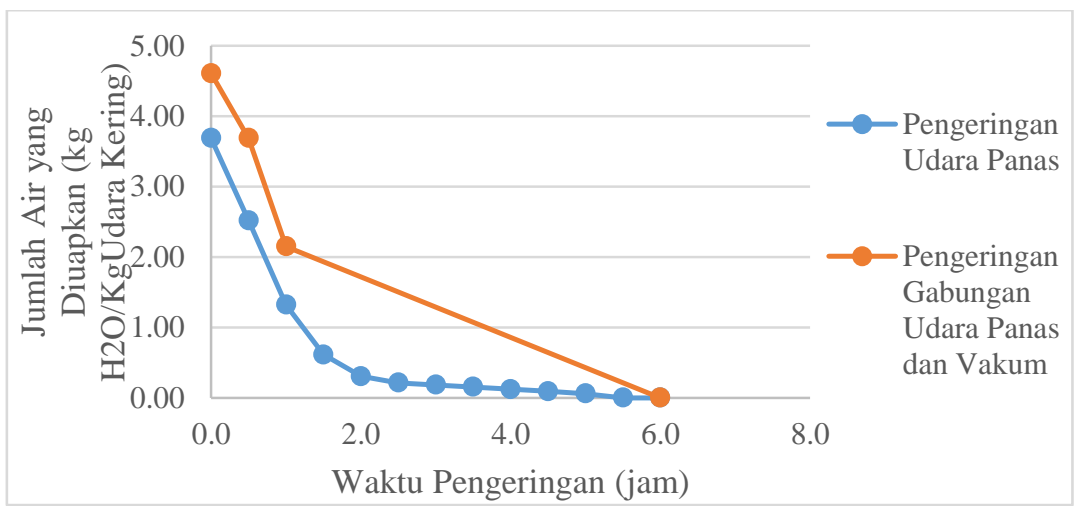

Gambar 7 Grafik hubungan jumlah air yang diuapkan dengan waktu pengeringan dengan massa bahan awal 200 gram

Jumlah air yang diuapkan pada kondisi pengeringan gabungan udara panas dan vakum lebih besar dibanding dengan pengeringan udara panas. Hal ini disebabkan karena sistem pengeringan vakum dapat menguapkan air lebih banyak. Pada sistem pengeringan vakum titik didih air akan lebih rendah dari $100^{\circ} \mathrm{C}$ sehingga air akan lebih cepat menguap pada kondisi pengeringan vakum dibandingkan pengeringan pada kondisi atmosferik.

Udara yang terdapat dalam proses pengeringan mempunyai fungsi sebagai pemberi panas pada bahan pangan, sehingga menyebabkan terjadinya penguapan air. Fungsi lain dari udara adalah untuk mengangkut uap air yang dikeluarkan oleh bahan pangan yang dikeringkan. Kecepatan pengeringan akan naik apabila kecepatan udara ditingkatkan. Kadar air akhir apabila mulai mencapai kesetimbangannya, maka akan membuat waktu pengeringan juga ikut naik atau dengan kata lain lebih cepat.

Faktor yang dapat mempengaruhi pengeringan suatu bahan pangan adalah sifat fisik dan kimia dari bahan pangan, meliputi bentuk, komposisi, ukuran, dan kadar air yang terkandung di dalamnya, pengaturan geometris bahan pangan, sifat fisik dari lingkungan sekitar alat pengering, meliputi shut, kecepatan sirkulasi udara, dan kelembaban, serta karakteristik dan efisiensi pemidahan panas alat pengering (Buckle dkk. 1985).

Proses pengeringan juga harus memperhatikan suhu udara dan kelembaban. Suhu udara yang tinggi dan kelembaban udara yang relatif rendah dapat mengakibatkan air pada bagian permukaan bahan yang akan dikeringkan menjadi lebih cepat menguap. Hal ini dapat berakibat terbentuknya suatu lapisan yang tidak dapat ditembus dan menghambat difusi air secara bebas. Kondisi ini lebih dikenal dengan case hardening.

Proses pengeringan dimulai pada saat makanan diletakkan pada alat pengering dan terjadi perpindahan air dari bagian bawah bahan pangan. Perpindahan ini disertai dengan evaporasi pada bagian permukaan, sehingga bagian permukaan makanan tetap dalam keadaan basah. Keadaan ini disebut dengan constant rate period, di mana keadaan ini tetap akan berlanjut sampai mencapai titik kandungan uap air tertentu. Gambar 8 menunjukan grafik kecepatan pengeringan. 


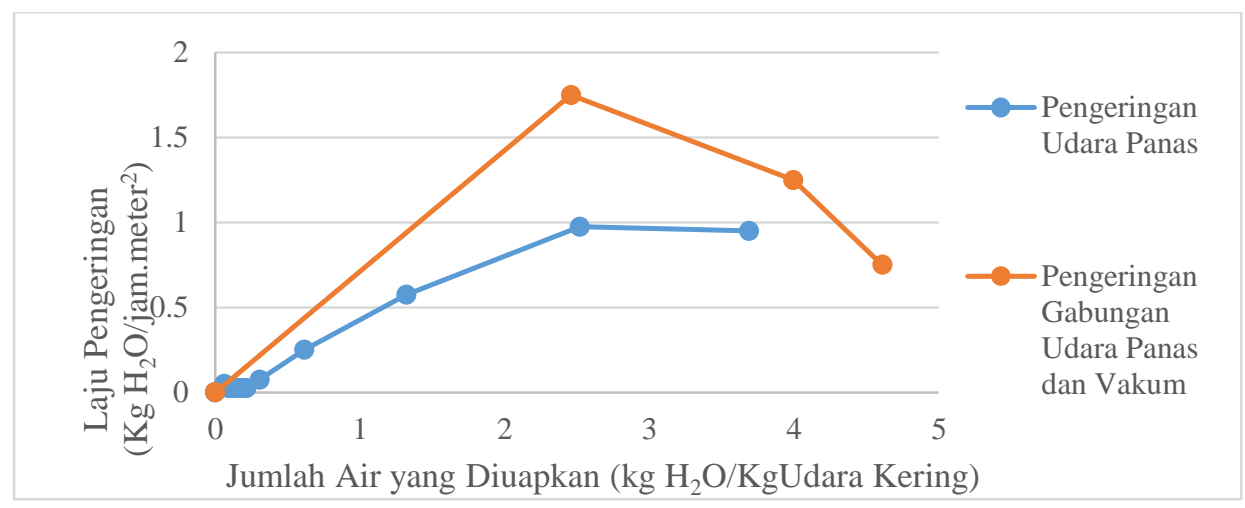

Gambar 8 Grafik kecepatan pengeringan dengan massa bahan awal 200 gram

Gambar 8 menunjukan bahwa laju pengeringan pada kondisi vakum lebih tinggi dibandingkan laju pengeringan pada keadaan atmosferik. Kurva laju pengeringan dalam periode laju pengeringan menurun berbeda-beda tergantung pada jenis bahan. Pengendalian laju pengeringan merupakan bagian optimasi proses dalam usaha mengendalikan mutu hasil pengeringan. Laju pengeringan yang terlalu cepat pada bahan pangan dengan laju pengeringan menurun, menyebabkan kerusakan fisik dan kimia pada bahan pangan. Terjadinya case hardening adalah bentuk kerusakan secara fisik akibat dari laju pengeringan yang kurang terkontrol. Hal ini disebabkan terjadinya kecepatan difusi dalam bahan pangan menuju permukaan tidak dapat mengimbangi kecepatan penguapan air di permukaan bahan. Sedangkan permukaan bahan sudah tidak seluruhnya jenuh dengan air, bahan makin berkurang terus sehingga pada permukaan terjadi penguapan sampai menjadi tidak jenuh dan merupakan tahapan dari kecepatan menurun yang kedua di mana kecepatan aliran atau gerakan air di dalam bahan menentukan kecepatan laju pengeringan.

Hasil penelitian tahap pertama menunjukan bahwa alat pengering hasil perancangan memiliki performa yang baik. Hal ini ditunjukan dengan nilai humiditi dari ruang pengering sebesar $0,0186 \mathrm{~kg}$ $\mathrm{H}_{2} \mathrm{O} / \mathrm{kg}$ udara kering dan tekanan yang stabil selama proses pengeringan yaitu sebesar $-61,5$ cmHg.

\section{Daftar Pustaka}

1. Buckle, K.A, R.A. Edward, G.H. Fleet, dan M. Wooton. (1985): Ilmu pangan, UI Press, Jakarta.

2. Geankoplis, CJ. (1993): Transport processes and unit operations. 2nd ed. Allyn and Bacon, Inc., 7 Wells Avenue, Newton, Massachusetts, USA.

3. Kementerian Pertanian. (2015): Produktivitas nangka di Indonesia. http://www.pertanian.go.id, akses : 20 Maret 2015. 